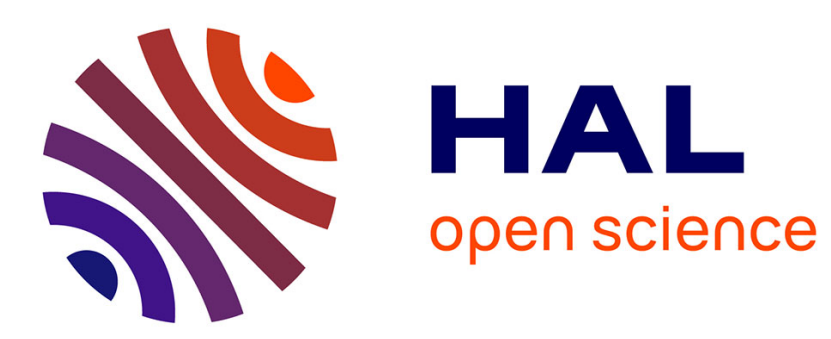

\title{
Mixed-Valence Defect Ferrites : a New Family of Fine Powders and Thin Films of Spinel Ferrites
}

\author{
P. Tailhades, B. Gillot, A. Rousset
}

\section{To cite this version:}

P. Tailhades, B. Gillot, A. Rousset. Mixed-Valence Defect Ferrites : a New Family of Fine Powders and Thin Films of Spinel Ferrites. Journal de Physique IV Proceedings, 1997, 07 (C1), pp.C1-249-C1-252. 10.1051/jp4:1997196 . jpa-00255143

\section{HAL Id: jpa-00255143 https://hal.science/jpa-00255143}

Submitted on 1 Jan 1997

HAL is a multi-disciplinary open access archive for the deposit and dissemination of scientific research documents, whether they are published or not. The documents may come from teaching and research institutions in France or abroad, or from public or private research centers.
L'archive ouverte pluridisciplinaire HAL, est destinée au dépôt et à la diffusion de documents scientifiques de niveau recherche, publiés ou non, émanant des établissements d'enseignement et de recherche français ou étrangers, des laboratoires publics ou privés. 


\title{
Mixed-Valence Defect Ferrites: a New Family of Fine Powders and Thin Films of Spinel Ferrites
}

\author{
P. Tailhades, B, Gillot* and A. Rousset
}

Laboratoire de Chimie des Matériaux Inorganiques, Université Paul Sabatier, ESR-CNRS 5070, 118 route de Narbonne, 31062 Toulouse cedex, France

* Laboratoire de Recherches sur la Réactivité des Solides, Université de Bourgogne, URA 23 du CNRS, BP. 138, 21004 Dijon, France

\begin{abstract}
When highly divided spinel ferrites become teactive enough with oxygen, to allow the oxidation of the $\mathrm{Fe}^{2+}$ ions at low temperature and of substitute cations ton, when these cations are capable of different valence states. We prepared fine particles of spinel ferrites substituted by $\mathrm{Mn}, \mathrm{Mo}, \mathrm{Cu}$, by "chimie douce", especially from oxalate precursors and used them to reveal and to study the oxido-reduction phenomena occurring in these finely divided materials. It was shown that the oxidation created a new family of spinel ferrites : the mixed-valence defect ferrites, having specific characteristics and properties. The ferrites of this type can be fine powders prepared at low temperature, or ground ferrites obtained at high temperature, or thin films.
\end{abstract}

\section{INTRODUCTION}

Many different spinel ferrites $\mathrm{X}_{\mathrm{X}} \mathrm{Fe}_{3-\mathrm{x}} \mathrm{O}_{4}\left(\mathrm{X}=\right.$ metallic cations) have already been prepared at high temperature $\left(>1000^{\circ} \mathrm{C}\right)$ by solid-solid reactions. These methods are very useful, not oniy in preparing samples for fundamental studies, but also for producing devices for microwave or other applications. Such applications mainly requires "bulk" ferrites (coarse particles, sintered ceramics, single crystals). Oxides prepared at high temperature are generally close to stoichiometry, with a metal/ oxygen ratio $(\mathrm{M} / \mathrm{O})$ close to $3 / 4$. However, the cation oxidation is difficult in these "bulk" oxides because of their poor reactivity to oxygen while the spinel structure is also generally lost as the $M / O$ ratio decreases. In fact, during the oxidation of coarse grains $(>300 \mathrm{~nm}$ ) of ferrites, the crystallographic transformation of the spinel lattice in corundum structure, has already been demonstrated [1][2]. It has been shown [3], however, that it is possible to oxidize $\mathrm{Fe}^{2+}$ cations in fine particle or thin film form, while keeping the spinel structure. Cation deficient spinel ferrites $(\mathrm{M} / \mathrm{O}<3 / 4)$ could then be obtained. These have been the subject of many works too, and they are, currently, widely used for magnetic recording pigments $\left(\gamma-\mathrm{Fe}_{2} \mathrm{O}_{3}, \mathrm{Co}\right.$-doped $\gamma-$ $\mathrm{Fe}_{2} \mathrm{O}_{3}$ ). Certain authors have tried to put the ferrite' reactivity to use in preparing high -performance magnetic materials. Their works mainly focused on the oxidation of the $\mathrm{Fe}^{2+}$ ions alone, in either pure [3][4] or substituted magnetite [5-7].

This paper concerns finely divided spinel ferrites substituted by mixed valence transition metals. The main feature of interest of these materials is that $\mathrm{Fe}^{2+}$ ions, and their substitution cations can both be oxidized to lead to the formation of defect spinel ferrites with mixed valence. Some of the resulting specific characteristics and properties, that make these phases a new family of ferrites are presented.

\section{PREPARATION OF FINE PARTICLES OF SUBSTITUTED SPINEL FERRITES}

Many methods have already been proposed for preparing small particles of spinel ferrites. Most are "chimie douce" methods, which can be subdivided into two main classes. In the first, the spinel ferrite particles are prepared directly by precipitating different metallic and iron salts in an alkaline medium. Depending on the $\mathrm{pH}$, concentrations, temperature and other conditions, the required particles are formed after ageing. The second class of methods consists in precipitating a precursor, containing the desired metallic ion/iron ion ratio, and then heat-treating it at low temperature to obtain a single spinel ferrite. Fine particles can be prepared by either of these methods.

A process of the second class was chosen to prepare our fine particles of substituted ferrites. The basic precursor was the ferrous oxalate $\mathrm{FeC}_{2} \mathrm{O}_{4}, 2 \mathrm{H}_{2} \mathrm{O}$. In this compound, iron can be totally or partially replaced by any of several metallic elements, especially $\mathrm{Mg}, \mathrm{Mn}, \mathrm{Co}, \mathrm{Ni}, \mathrm{Zn}, \mathrm{Cu}$... Two types of heat treatment are generally required in succession to transform the precursor into a spinel fcrrite. The first, in air, breaks the oxalate particles down into both a spinel oxide and a corundum typephase. The second is carried out under a reductive $\mathrm{H}_{2}-\mathrm{N}_{2}-\mathrm{H}_{2} \mathrm{O}$ atmosphere, to form a pure spinel phase. If small needle-like particles are wanted (fig. 1), a very slow decomposition of oxalates particles, precipitated in an alcoholic medium, is required [8]. Moreover, all the heat treatments have to be performed at as low as possible temperature. 


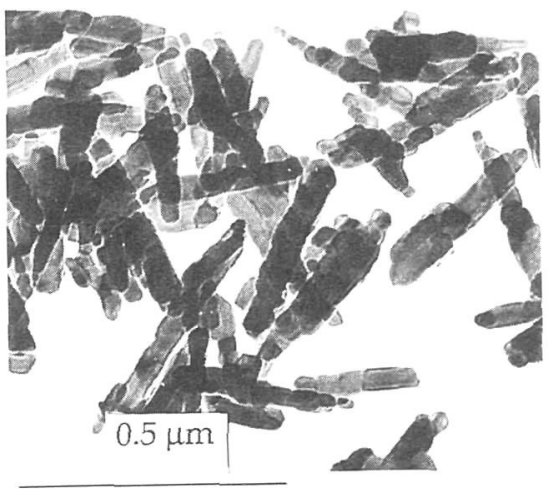

Figure 1: Acicular particles of $\mathrm{Co}-\mathrm{Mn}$ spinel lerrites prepared from oxalic precursors.

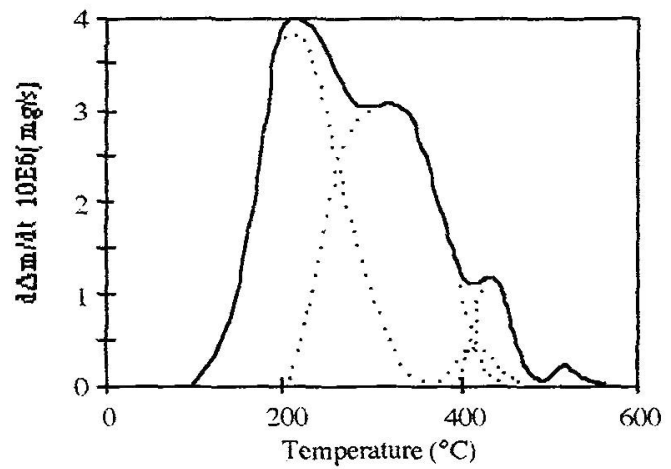

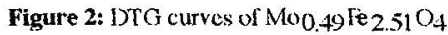
(Oxygen pressure: $40 \mathrm{hPa}$, heating rate: $2^{\circ} \mathrm{C} / \mathrm{min}$ )

Most of the spinel powders studied in this paper were elaborated from oxalic precursors. Mixed oxide particles, precipitated in alkaline medium, were used to prepare the $\mathrm{Mo}_{x} \mathrm{Fe}_{3-x} \mathrm{O}_{4}$ samples, because of the difficulties involved in precipitating Fe-Mo mixed oxalates.

\section{FINELY DIVIDED SUBSTITUTED SPINEL FERRITES : CATIONIC DISTRIBUTION AND REACTIVITY}

As small $\mathrm{X}_{\mathrm{X}} \mathrm{Fe}_{3-\mathrm{x}} \mathrm{O}_{4}$ particles of spincl ferrites oxidize, the oxygen lattice remains cubic close packed, and the oxygen ions are added to the structure as soon as the cations migrate to the surface and change their valence state. The reaction can be described as: $\mathrm{X}_{\mathrm{X}} \mathrm{Fe}_{3 \times \mathrm{x}} \mathrm{O}_{4}+\delta / 4 \mathrm{O}_{2} \rightarrow \mathrm{X}_{\mathrm{X}} \mathrm{Fe}_{3-\mathrm{x}} \mathrm{O}_{4+\delta / 2}=\mathrm{X}_{8 \mathrm{x}}(8+\delta) \mathrm{Fe}_{(248 \mathrm{x}) /(8+\delta)] 3 \delta(8+\delta)} \mathrm{O}_{4}$. ( $\delta$ is the number of exchanged electrons per formula unit, $\square$ represents the cationic vacancies). This equation shows that the resulting ferrite has a defect structure. If we assume that the molar mass of the ferrite is always close to 230 grams, the relative weight gain associated to the reaction is ( $8.0 x y$ gen atomic mass ) $/$ (molar mass of the ferrite) $=3.5 \cdot 10^{-2} .8$. The symmetric thermobalances, able to measure weight variations less than $0.01 \%$, can thus detect less than 0.003 electrons exchanged per formula unit during the oxidation. This very high sensitivity makes thermogravimetry a very good iool lor studying the specific reactivity of the spinel ferrites. Moreover, because the crystallite size distribution is not too large in ferrites prepared by the process previously described, differential thermogravimetry (DTG) reveals one single peak for each type of cation oxidized. Each peak is centered around a temperature depending on the coordination, the chemical nature, and the valence of the cations.

In fact, because the cation-oxygen bondings are more covalent on tetrahedral sites, the cations are more difficult to oxidize in this coordination than on octahedral sites. This is well demonstrated by the oxidation of powders of $\mathrm{Fe}_{3} \mathrm{O}_{4}$ and $\mathrm{Cr}_{2} \mathrm{FeO}_{4}$ with crystallite sizes close to $50 \mathrm{~nm}$. Fe ${ }^{2+}$ ions alone can be oxidized in these compounds, but in the first onc, Fe ${ }^{2+}$ ions are

Table 1: Structural formulae determinal from DTG measurements for the fine particles (crystallite size \# $50 \mathrm{~nm}$ ) of manganese, molybdenum and copper ferrites. $\left[M^{n+}\right]$ and $M^{n+}$ : represents cations on octahedral and tetrahedral sites respectively, $\alpha \# 0.1, \gamma+\gamma_{10} 0.015, \beta$ and a are increasing functions of $x, b$ is a decreasing function of $x$. Reaction 3 is partial (\#5)\% of $\mathrm{Mn}^{2+}$ oxidized).

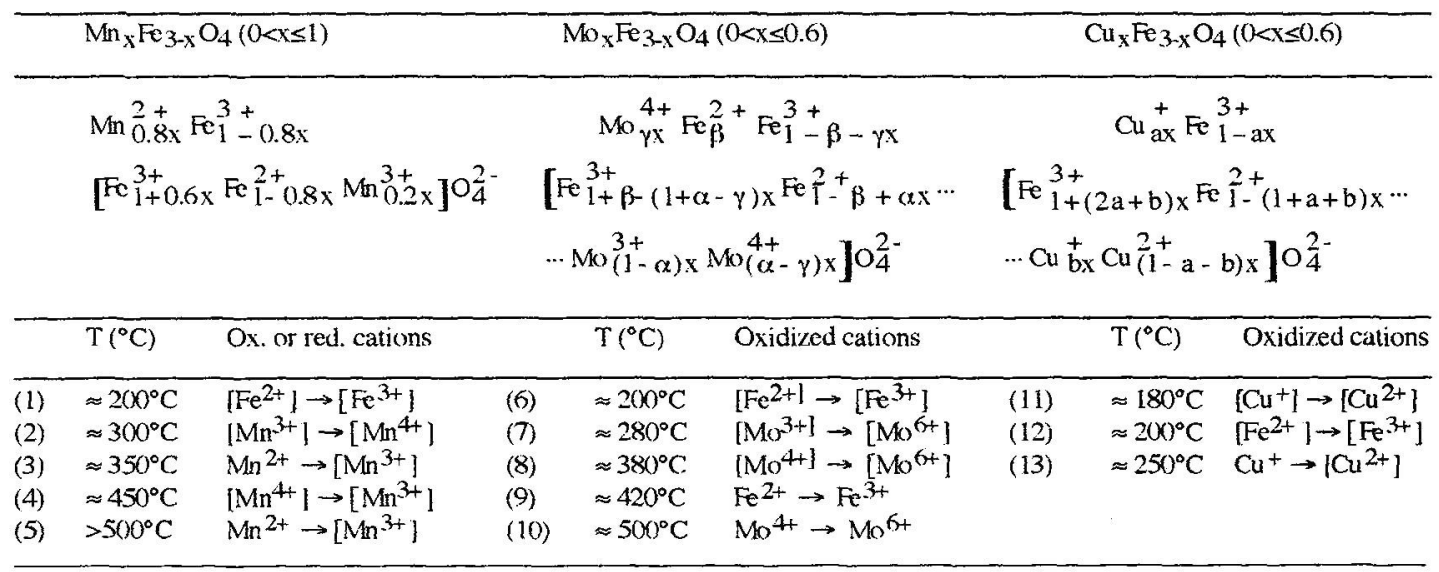


located on octahedral sites, while they are in a tetrahedral surrounding in the second. The DTG analyses reveal that octahedral and tetrahedral $\mathrm{Fe}^{2+}$ ions are oxidized around $200^{\circ} \mathrm{C}$ and 40$)^{\circ} \mathrm{C}$ respectively $\left.19 \| 10\right]$. Moreover, the oxidation temperature depends on the chemical nature and the valence state of the ions $[10]$. For this reason, besides the peaks ascribed to the Fe $2+$ ion oxidation, other DTG peaks may appear for ferrites substituted by those ions capabic of adpot several valence states (fig. 2). By combining several techniques we were able to identify cach peak in the oxido-reduction process of manganese [11][12], molybdenum [13][14] and copper [15] substituted ferrites elaborated by a "chimie douce" process. Because the surface area of a given DTG peak is proportional to the quantity of the oxidized ions, by measuring the surface area of each peak after desummation of the DTG curves, we can calculate the quantity of each oxidizable cation in the stoichiometric ferrite. This makes thermogravimetry a quantitative method for determining the structural formula of the spinel ferrites. The structural formulae of $\mathrm{Mn}_{x} \mathrm{Fe}_{3-\mathrm{x}} \mathrm{O}_{4}(0<\mathrm{x} \leq 1)[16], \mathrm{Mo}_{x} \mathrm{Fe}_{3} \mathrm{O}_{4} \mathrm{O}_{4}(0<\mathrm{x} \leq 0.5)$ [13] or $\mathrm{Cu}_{x} \mathrm{Fe}_{3-\mathrm{x}} \mathrm{O}_{4}(0<\mathrm{x} \leq 0.6)$ [15] fine particles of spinel ferrites were refined by this method (tab. 1).

Ferrites obtained at high temperature can also be ground to sufficiently small grain sizes to make the above oxido-reduction phenomena possible. Therefore, the reactivity of ground $\mathrm{Mo}_{x} \mathrm{Fe}_{3-\mathrm{x}} \mathrm{O}_{4}(0<\mathrm{x} \leq 1)[17), \mathrm{Cu}_{\mathrm{x}} \mathrm{Fe}_{3-\mathrm{x}} \mathrm{O}_{4}(0<\mathrm{x}<\leq 1)\left\{15 \mid\right.$ and $\mathrm{V} \mathrm{Fe}_{3}$ ${ }_{x} \mathrm{O}_{4}(0<x \leq 1)[18]$ was studied and it was found, in spite of certain slight differences, these have cationic distributions similar to what is obtained by "chimie douce". Moreover, the heat treatments in air also lead to the formation of the high valence state of manganese $\left(\mathrm{Mn}^{4+}\right)$ and molybdenum $\left(\mathrm{Mo}^{6+}\right) . \mathrm{V}^{5+}$ ions were found in spinel ferrites for ground samples [18].

More complicated fine powders of $\mathrm{Co}-\mathrm{Mn}, \mathrm{Co}-\mathrm{Mo}$ and $\mathrm{Co}-\mathrm{Cu}$ spinel ferrites were also prepared by "chimie douce". In these oxides the cobalt ions are $\mathrm{Co}^{2+}$. They are mainly located on octahedral sites when the cobalt content is low, and they are distributed on both sites when the cobalt content per formula unit, is relatively high (0.8-1) [19][8]. Therefore, cobalt ions replace the bivalent cations of the lattice ( $\left.\mathrm{Fe}^{2+}, \mathrm{Mn}^{2+}, \mathrm{Cu}^{2+}\right)[8][19-21]$. Most of the oxido-reduction reactions, given in table 1 , remain the same in spite of the cobalt substitution. As soon as the bivalent cations are replaced by stable Co ${ }^{2+}$ ions, the reactions involving these cations arc obviously removed 18$]$.

\section{A NEW FAMILY OF SPINEL FERRITES}

The oxidations previously described generate unusual high valence states for $\mathrm{Mn}, \mathrm{Mo}$ and $\mathrm{V}$ cation in spinel ferrites. This is one of the specific characteristics of the phases studied. For instance, $\mathrm{Mn}^{4+}$ ions are not encountered in bulk ferrites, whose poor reactivity makes oxidation possible only in a range of temperatures where $\mathrm{Mn}^{4+}$ ions are not stable. Another consequence is the creation of spinel phases having a great number of vacancies. This can be shown by the oxidation of molybdenum ferrites (reactions (6) to (10) in table 1). In fact, the complete oxidation is described by: $\mathrm{Mo}_{\mathrm{x}-\alpha \mathrm{x}}^{3+} \mathrm{Mo}_{\alpha x}^{4+} \mathrm{Fe}_{1+\alpha x}^{2+} \mathrm{Fe}_{2-\mathrm{x}-\alpha \mathrm{x}}^{3+} \mathrm{O}_{4}^{2-}+\frac{1+3 \mathrm{x}}{4} \mathrm{O}_{2} \rightarrow \mathrm{Mo}_{8 \mathrm{x} /(9+3 \mathrm{x})}^{6+} \mathrm{Fe}_{(24-8 \mathrm{x})(9+3 \mathrm{x})}^{3+}\left[\mathrm{l}_{(3+9 x)(9+3 \mathrm{x})} \mathrm{O}_{4}^{2-}\right.$

When $x$ is close to 0.6 , for the richest molybdenum ferrite prepared now by "chimie douce", the oxidation can generate a defect spinel phase containing around 0.78 vacancy per formula unit. The $M / O$ ratio $(0.56)$ is then very much less than $3 / 4$ and even less than $2 / 3$, which are the $\mathrm{M} / \mathrm{O}$ ratios for the non-oxidized ferrites and the well-known $\gamma$-Fe2 $\mathrm{O}_{3}$ defect spinel phase, respectively.

The oxidations proceed from the surface to the core of the grains. When the particles are partially oxidized, the outer part (highly oxidized) and the inner part (weakly or not oxidized) have small and large unit cells respectively. In fact, the more the ferrite is oxidized, the lower its lattice constant. To simplify, it may be assumed that the accomodation of the two spinel lattices thus tends to develop a tension near the surface and a compression in the core. The resulting stress, which reaches a maximum at around half oxidation, may cause an enhancement of the coercive force due to induced magneto-clastic effects, and also probably creates a directional order (DO) [22]. In fact, the DO, which reveals the minimization of the fattice free energy, appears under the effect of the magnetization and not only heat treatments or irradiation, but also mechanical stress. The establishment of the DO has a very low kinetic. Generally, special heat treatments are required to complete the DO creation.

Experimentally, enhancements in coercivity $(\mathrm{Hc})$ due to partial oxidations are mainly revealed in cobalt-substituted ferrites because of the strong magneto-elastic effects of cetahedral $\mathrm{Co}^{2+}$ ions. For the same reasons, major variations in the remanent Faraday rotation are also observed in these oxides $\left(\theta_{F, R}\right)[23]$. The curves of rom temperature Hc (or $\left.\theta_{F, R}\right)$ versus oxidation temperature for these materials show different peaks centered in the regions where approximatively.half of each type of oxidizable cation have changed valence. The more important oxidations are then revealed by the coercive force measurements (fig. 3-4), not only for fine powders but also for thin films made of fine crystallites. However, in spite of the small crystallite sizes (about $20 \mathrm{~nm}$ ) in the films, the oxidations occur at higher temperatures than for powders. In fact, the films surface in contact with air during oxidation is very small, because of the close packing crystallites and the protection of one side of the film by a substratc. This slows down the oxidation kinetics and shifts the reactions to high temperatures.

In spite of the cnhancements in Hc due to the partial oxidation, it is possible to improve Hc further by a more complete DO This can be done by cooling the samples very slowly at about $10^{\circ} \mathrm{C} / \mathrm{h}$ from their oxidation temperature to room temperature. Extraordinary/coercivities (of about 4000 Oe for $\mathrm{Mo}_{0.1} \mathrm{Co}_{0.92} \mathrm{Fe}_{1.98} \mathrm{O}_{4}$ [21]) can be achieved this way for fine powders of spinel ferrites.

For pure manganese ferrites, oxido-reduction phenomena arcund $450^{\circ} \mathrm{C}$ create many $\mathrm{Mn}^{3+}$ ions. When the total manganese content is high $(x \geq 1)$, the $\mathrm{Mn}^{3+}$ content is above the critical concentration for which the spinel lattice becomes telragonally distorted, because of the cooperative Jahn-Teller effect. Besides creating the mised valence defect structure, the reactivity in this case causes the loss of the latice cubic symmetry. The unit ecll distortion gencrates an anisotropy 


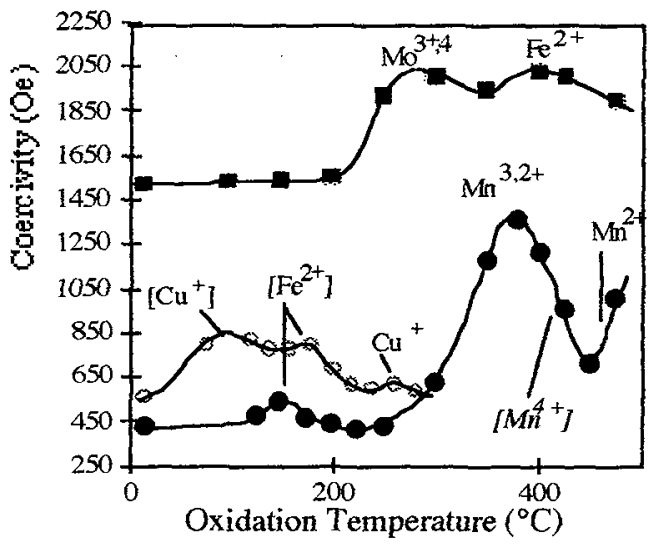

Figure 3: Coercivity versus oxidation temperature for $\mathrm{Mn}_{0.4} \mathrm{Co}_{0.18} \mathrm{Fe}_{2.42} \mathrm{O}_{4}, \mathrm{Cu}_{0.18} \mathrm{Co} 0.18 \mathrm{Fe}_{2.64} \mathrm{O}_{4}, \mathrm{Mo}_{0.1} \mathrm{Co}_{0.92} \mathrm{Fe}_{1.98} \mathrm{O}_{4}$ quenched after oxidation at different temperatures. $\left[\mathrm{M}^{\mathrm{n}+}\right]$ and $\mathrm{M}^{\mathrm{n}+}$ are octahedral and tetrahedral cations oxidized or reduced

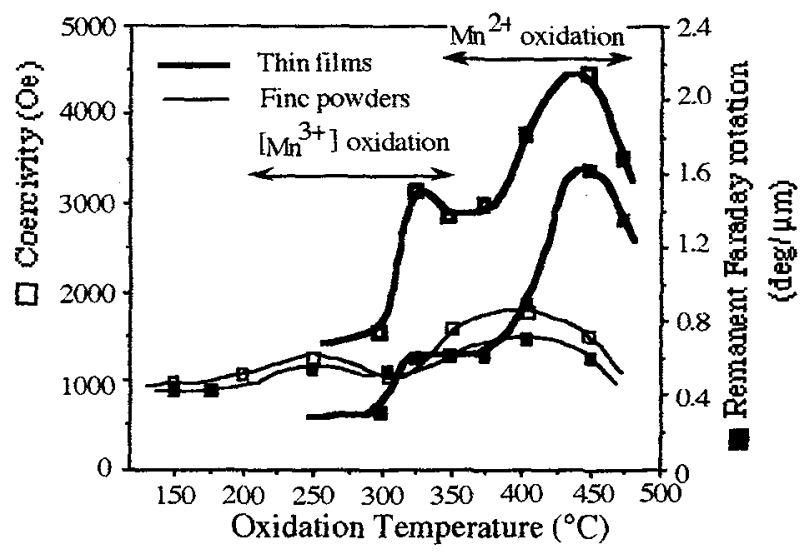

Figure 4: Coercivity and remanent Faraday rotation for $\mathrm{Mn}_{0.13} \mathrm{Co}_{0.73} \mathrm{Fe}_{2.14} \mathrm{O}_{4}$ thin film and $\mathrm{MnO}{ }_{12} \mathrm{Co}_{08} \mathrm{Fe}_{2.08} \mathrm{O}_{4}$ fine powder oxidized at different temperatures.

which has an effect on the coercivity. Fine acicular particles of $\mathrm{MnFe}_{2} \mathrm{O}_{4}$ and $\mathrm{Mn}_{1.8} \mathrm{Fe}_{1.2} \mathrm{O}_{4}$ have coercivities close to 175 and 90 Oe respectively, before oxidation, but these last reach 325 and 860 Oe after an oxidation at $425^{\circ} \mathrm{C}$ for 2 hours.

From the above examples, it is clear that the formation of mixed valence cations and vacancies endows ferrites with specific characteristics and properties. This makes the mixed-valence defect ferrites a truly new family of spinel ferrites.

\section{CONCLUSION}

Finely divided ferrites have enough reactivity with oxygen that it becomes possible not only to oxidize the ferrous ion in the spinel lattice, but also the substitute cations, when these cations are capable of different valence states. Mixed-valence defect ferrites can then be created. Their properties are sufficiently different from those of the stoichiometric ferrites from which they derive, that they can be considered to constitute a new family. These new materials may be fine particles, prepared by a "chimie douce" or by grinding ferrites obtained at high temperature; or they may be thin films. Some of the mixed valence defect ferrites properties $\left(\mathrm{Hc}_{\gamma} \theta_{\mathrm{F}, \mathrm{R}}\right)$ are already of interest for information storage purpose, and carefull study of their electric, electromagnetic, and optical properties should reveal other potential applications of this new family of spinel ferrites.

\section{References}

[1] Feiktnecht W., Mannweiler U., Helv. Chim. Acta, 45, (1962), 2042-2049

[2] Gallagher K. J., Feitknecht W., Mannweiler U., Nature, 217, (1968), 1118-1121.

[3] Langlet M., Joubert J. C., J. A ppl. Phys. 64, (1988), 780-786.

[4] Imaoka Y., J. Electrochem. Soc. Japan, 36, (1968), 15-22.

[5] Sasazawa K., Shimizu M., Kitamoto T., Ger. Patent (1975), 2510799.

16] Sasazawa K., Yamada Y., Kitamoto T., A kashi G., Japan. Patent (1976), 7602998.

[7] Mollard P., Collomb A., Devenyi J, Rousset A., Paris J., IEEE Trans. Mag. 11, (1975), 894-898.

[8] Chassaing 1., Presmanes L., Tailhades Ph., Rousset A., Solid State Ionics 58, (1992), 261-267.

[9] Gillot B., Ferriot J., Dupre G., Rousset A., Mater. Res. Bull. 11, (1976), 843-848.

[10] Gillot B., Rousset A., HCR Comprehensive Review, 1, (1994), 69-98.

[11] Tailhades Ph., Rousset A., Bendaoud R., Fert A.R., Gillot B., Mater. Chem. Phys. 17, (1987), 521-529.

[12] Gillot B., El Guendouzi M., Tailhades Ph., Roussel A., Reactivity of Solids 1, (1986), 139-152.

[13) Domenichini B., Gillot B., Ph. Tailhades Ph., Bouet L. Rousset A., Perriat P., Solid State Ionics 58, (1992), 61-69.

[14] Bouet L., Tailhades P., Rousset A., Kannan K.R., Verelst M., Kulkarni K.U., Rao C.N.R., J. Sol State Chem. 102, (1993), 414-422.

[15] Kester E., Gillot, Perriat P., Dufour Ph., Villette C., Tailhades Ph., Rousset A., J. Sol. St. Chem. (to be published).

[16] Laarj M., Pignone I., El Guendouzi M., Tailhades Ph., Rousset A., Gillot B., Thermochimica Acta 152, (1989), 187-195.

[17] Domenichini B., Gillot B., Tailhades Ph., Perriat P., Thermochimica Acta 205, (1992), 259-269.

[18] Nohair M, Perriat P., Domenichini B., Gillot, Thermochim. Acta, 244, (1994), 223-234.

[19] Tailhades Ph., Mollard P., Rousset A., Gougeon M., IEEE Trans. Mag. 26, (1990), 1822-1824.

[20] Villette C., Tailhades Ph., Rousset A., J. Sol. State Chem., 117, (1995), 64-72.

[21] Tailhades Ph., Bouet L., Gillot B., Mollard P., Rousset A. Proceedings or ICF 6, Japan, (1992), $991-994$.

[22] Néel L., J. Phys. Rad. 15, (1954), 225-239.

[23] Bouet L., Tailhades Ph., Rousset A., J. Mag. Mag. Mater. 153, (1996), 389-396. 